\title{
Asthma mortality: summary of a round-table discussion, New York, January 1997
}

Variations in death certificate designations, uneven rates of diagnosis during life and differences in prescribing patterns conspire to make the data on asthma mortality difficult to assess, but different countries have experienced increasing, decreasing or stable mortality rates for asthma in recent years. However, despite what is perceived as an improved understanding of the disease and availability of apparently effective therapies, there has been no major long-term reduction in morbidity or mortality worldwide. Many hypotheses for this perceived failure have been proposed. The testing of such hypotheses requires large numbers that can only be acquired and analysed using epidemiological tools. Limitations on data imposed by the sources and the limits on the kinds of data that can be collected prospectively create a challenge that is not easily met.

The purposes of the Respiratory Epidemiology Round Table were to review the available worldwide data on asthma mortality, agree on the unanswered questions and identify the methodology that should be used to answer them in the future. The approach taken to achieve these goals was to designate four areas that may relate to asthma mortality: definition of patients at risk, environment, undertreatment, and overtreatment.

\section{Patients at risk}

Many facets have been explored to identify asthmatic patients at risk for fatal or near-fatal episodes. Demographic aspects including older age, lower socioeconomic status, related factors of less access to and poorer quality medical care and ethnic origin have been identified as potentially important in assessing risk. In small studies, certain physiological features suspected of contributing to risk include a lack of awareness of residual obstruction after attacks and less dyspnoea in response to hypoxia and hypercapnoea. However, in epidemiological studies the best predictor of mortality is having experienced hospitalization for asthma in the previous 12 months, particularly if there was a need for mechanical ventilatory support. An exception to hospitalization as a risk predictor is found in younger age groups $(<12 \mathrm{yrs})$ in whom the hospitalization rate is quite high, yet the mortality rate is low and a high proportion of the deaths occur in those who are thought to have only mild or moderate asthma [1]. The older age group ( $>65 \mathrm{yrs}$ ) accounts for more than half of the morta- lity in asthma, suggesting that co-morbid processes, e.g. chronic obstructive pulmonary disease (COPD), may play a role.

The differences between the at-risk groups that have crescendo asthma with deteriorating lung function over days, requiring increased medication, and those who experience sudden fatal or near-fatal attacks without apparent warning, are considerable, so that there are probably at least two high-risk groups. It is obvious that both groups have severe disease but, based on pre-event criteria, it is clear that different indices of severity must exist. Thus, better indicators of severity are needed than those now in use to identify those patients who are apt to suffer fatal or near-fatal attacks. Severity and control appear to be only loosely related variables. Whereas some severe disease can be controlled with medication, the mild disease that may precede sudden fatal or near-fatal attacks is certainly not controlled. More comprehensive and reliable databases than those available now will be required to stratify risk levels more completely and more attention needs to be given to the psychosocial characteristics of those who die from asthma.

\section{The environment and asthma deaths}

Environmental factors that contribute to asthma deaths are relatively poorly understood, in part because the subject is difficult to study and has been largely ignored. The environment may have an immediate or possibly a delayed influence on the eventual death of a patient.

There is little evidence that outdoor air pollution, as usually understood, has any significant effect on asthma deaths [2]. This conclusion, however, relates to a rather general definition of air pollution and ignores the possibility that specific pollutants or even mixtures of pollutants might be important.

Exposure to allergens may be of greater importance. Mortality among young asthmatic patients is increased in the late summer and autumn when there is an increased exposure to some seasonal allergens. Increases in acute severe asthma and asthma deaths have been reported following exposure to moulds [3-5] and to soya bean dust [6]. Occupational studies have only very rarely identified fatal events even though these have examined exposures to allergens in far greater concentrations than those found in the ambient atmosphere. However, much smaller doses

Participants: U. Ackermann-Liebrich, H. Ross Anderson, J. Anto, R. Beasley, A.S. Buist, P. Burney (co-chair), P. Ernst, P. Gergen, R. Ingram (co-chair), S. Lanes, N. Pearce, C. Reed, B. Rijcken, S. Suissa, P. Vermeire, A. Walker

This report was edited by P. Burney and R. Ingram on behalf of the participants.

Correspondence: P. Burney, Dept of Public Health Sciences, King's College, 42 Weston Street, London SE1 3QD, UK. Fax: 44171 4034602

The meeting was sponsored by GlaxoWellcome 
may be fatal in highly susceptible individuals under certain conditions and such individuals would probably be selected out of exposed workforces.

There is some evidence that asthma attacks during epidemics associated with allergens are different in nature to those at other times, with a much shorter duration, as recorded by the time required for ventilation and the length of admission to hospital.

The role of indoor allergens in asthma deaths is again poorly understood. Although there is some published evidence that the levels of indoor allergens in the homes of patients who died of asthma are not particularly high, there is evidence that acute severe asthma may be associated with exposure to high ambient levels of indoor allergens [7]. It is possible that the pattern of exposure to allergens may be critical, with peaks of high exposure interspersed with periods of low or no exposure being particularly dangerous.

The role of viruses in asthma deaths is unclear, although they must come under suspicion. There is now good evidence that viruses are potent initiators of asthma attacks, particularly in children, although they have very low rates of asthma mortality.

\section{Undertreatment}

The availability of many therapies and the demonstrated effectiveness of some of these in studies with limited numbers of patients provides the temptation to extrapolate to larger populations. The ultimate test requires epidemiological approaches. $\beta$-Agonists are the most frequently used drugs. They are effective and it is doubtful that these agents are underused in treatment. Several questions remain, however, including the safety of long-acting formulations, the safety of regular or frequent use in severe asthma, the potential for aggravation of asthma over time and the acute effects under conditions of hypoxia.

Given that inflammation is an integral part of asthma, inhaled anti-inflammatory agents, specifically glucocorticoids, should play a prominent, even dominant, role in therapy. In relatively small prospective studies, these agents have been shown to decrease the responsiveness of asthmatic lungs to nonspecific stimuli and to diminish the occurrence of events, including hospitalization rates. Ecological studies of secular trends indicate that asthma mortality drops as inhaled steroid prescriptions and sales increase; further, hospitalization rates decrease with regular inhaled steroid usage. Not all studies agree with these encouraging trends; however, overall, the data provide strong support for the beneficial effects of inhaled steroids and there is a general perception that these are underutilized in some countries.

The long-term questions yet to be answered include: whether they alter the long-term natural history of the disease, the safety of long-term usage, the incidence and severity of systemic effects such as glaucoma, cataracts and osteoporosis and the potential influence on growth and development in adolescent children.

\section{Overtreatment}

The hypothesis that $\beta$-agonists pose a risk to life was first suggested in a study which showed that patients who used adrenaline sprays were at increased risk of death [8]. In the 1960s several countries experienced an epidemic of asthma deaths which were ascribed to the sale of highdose isoprenaline [9]. In the 1980s a further epidemic of asthma deaths in New Zealand prompted a series of casecontrol studies which linked the $\beta$-agonist fenoterol to the increase in deaths [11-12]. A further study in Canada, although showing a higher mortality in those prescribed fenoterol, concluded that fenoterol could not be implicated as a cause of the increased mortality, since a pattern of increasing use of any $\beta$-agonists over time was strongly associated with asthma mortality and this was deemed a good marker of severity [13-15].

There is now a general acceptance that the heavy and increasing use of inhaled $\beta$-agonists is a marker of an increased risk of death from asthma. However, there is disagreement over four possible but not mutually exclusive explanations.

Heavy use of $\beta$-agonists may simply be a marker of very severe asthma, with any association between their use and death being coincidental

Severity in this context is the probability of death in the absence of treatment and differs from control of the disease as reflected in the clinical state of the patient. The observable state of the patient is almost always confounded and modified by treatment and other factors. Neither the amount of treatment taken nor the clinical state of the patient is a direct measure of severity in this sense. Furthermore, it is clear that children can have severe clinical disease with frequent hospitalizations but be at low risk of death.

Most researchers now agree that the increasing risk of death observed with increasing doses of bronchodilator used before death probably reflects true confounding by severity. The dispute is over whether the choice of a particular agent may lead to adverse consequences.

Fenoterol is a potent bronchodilator and was sold in high doses. It is, therefore, plausible that it was dispensed to those who had more severe disease. However, although the Canadian data [16] and some data from Auckland [17] showed that fenoterol was more likely to be prescribed to those with the more severe disease, the three national case-control studies in New Zealand did not. As fenoterol had a smaller share of the total market in Canada it may have been more likely to be differentially prescribed there than in New Zealand and it has been questioned whether the data from Canada or even Auckland are relevant to the interpretation of the national New Zealand studies.

In the case-control studies from New Zealand, controls were selected in order to minimize bias by severity. When those with known markers of severity, such as a previous admission to hospital, use of oral steroids and use of more than two categories of asthma medication, were looked at separately, the estimate of the relative risk of death associated with taking fenoterol increased with increasing severity of disease. It was argued that this made residual confounding by severity unlikely [18]. There are, however, three continuing areas of debate relating to this argument. 1) It has been questioned whether the markers used were relevant measures of severity [19]. In the first two New Zealand studies the controls had been indirectly 
matched for severity through the use of asthma hospital admission controls; such matching makes it impossible to assess the association between the severity markers and the risk of asthma death. However, in the third New Zealand study an additional unmatched control group was also used and it was found that all three severity markers were associated with risk of asthma death; in particular, there was a significant association between hospitalization in the previous 12 months and subsequent death from asthma [20]. 2) This cannot discount the possibility that other measures of severity are related both to the risk of death and to the type of bronchodilator prescribed. Such residual confounding would be particularly problematic if it were most marked within the more extremely ill subjects. 3) What was shown was not a lack of confounding by severity but effect modification by severity, this is that the effect of fenoterol was only seen in the most severe group. The interpretation of this must be different (see below).

Overuse of inhaled $\beta$-agonists may increase sensitivity of the airway and asthma severity [21]

There is evidence for some short-term rebound hyperresponsiveness in those who stop taking $\beta$-agonists, but current evidence suggests that regular $\beta$-agonists do not lead to any measurable loss of control, at least in mild asthma [22].

\section{At least some forms of $\beta$-agonist could affect the myocardium}

There is epidemiological evidence that theophylline, and both oral and nebulized (but not other inhaled) $\beta$ agonists were associated with cardiac deaths in asthma patients [23] and there is experimental evidence to suggest that $\beta$-agonists may have adverse effects on the myocardium [24-27]. Although these effects are generally very small in well oxygenated patients, they may kill patients with very severe asthma who become hypoxic. In the New Zealand studies the results were stratified by severity in order to take account of any confounding by severity. What was found was not "confounding" as it is generally understood, but "effect modification". That is, the association between being on fenoterol and the chances of death was stronger in the severe than in the mild cases. This complicates the interpretation of the analysis.

Effect modification by severity is biologically plausible if the cardiac effects of fenoterol are greater than those of salbutamol and are particularly marked in the presence of hypoxia. This is certainly compatible with the hypothesis that the increase in deaths in New Zealand was due to the use of fenoterol by severe asthmatics and that their deaths were caused by the cardiac effects of the drug in the presence of hypoxia. If asthma was more severe in New Zealand this interaction might also explain why the very severe epidemic in New Zealand was not replicated elsewhere. However, this does not readily explain the very rapid decline in admissions with asthma as well as mortality from asthma in New Zealand following 1988.

\section{$\beta$-Agonists could delay the use of more potent therapies}

This could explain the increasing use of $\beta$-agonists in the period leading up to death. It could not explain the sudden increases in asthma mortality reported in some countries, for which another explanation would need to be found.

There is general agreement that studies of time trends and differences between countries are hard to interpret because of differences in definitions of asthma between countries and the presence of hypothesized interactions. However, some conclusions can be drawn from them. The first is that whatever the effects of fenoterol, there are clearly other factors influencing mortality rates. This can be seen from the mortality trends in the USA, which has experienced a major increase in asthma mortality, particularly among African-Americans, and yet has never licensed fenoterol. It has also been argued that the sales of fenoterol in New Zealand are not enough on current calculations to explain the entire excess of deaths during the epidemic. Nevertheless, the approximate time course of the epidemic in New Zealand is similar to that of the sales of fenoterol.

Much has been said on the $\beta$-agonist controversy, but it should be noted that other medications, including theophyllines, have also been associated with excess asthma deaths [13]. Many of the same reservations can be made about these findings as can be made of the $\beta$-agonists. The principal difficulties remain that there is no clear single hypothesis that links the asthma deaths with the medication, there are no suitable markers of severity that predict death independently of health service use and there remains relatively little precise information relating to patients with asthma who have died.

\section{References}

1. Robertson CF, Rubinfeld AR, Bowes G. Pediatric asthma deaths in Victoria: the mild are at risk. Pediatr Pulmonol 1992; 13: 95-100.

2. Department of Health. Committee on the Medical Effects of Air Pollution Episodes. Asthma and outdoor air pollution. London, HMSO, 1995.

3. Jenkins PF, Mullins J, Davies BH, Williams DA. The possible role of aeroallergens in the epidemic of asthma deaths. Clin Allergy 1981; 11: 611-620.

4. O'Halloran MT, Yunginger JW, Orford KD, et al. Exposure to an aeroallergen as a possible precipitating factor in respiratory arrest in young patients with asthma. $N$ Engl J Med 1991; 324: 359-363.

5. Targonski PV, Persky VW, Ramekrishnan V. Effect of environmental molds on risk of death from asthma during the pollen season. J Allergy Clin Immunol 1995; 95: Pt 1, 955-961.

6. Anto J, Sunyer J, Rodriguez-Roisin R, Suarez-Cevera M, Vazquez L, and the Toxicoepidemiologic Committee. Community outbreaks of asthma associated with inhalation of soybean dust. N Engl J Med 1989; 320: 1097-1102.

7. Rosenstreich DL, Eggleston P, Kattan M, et al. The role of cockroach allergy and exposure to cockroach allergen in cousins morbidity among inner-city children with asthma. N Engl J Med 1997; 336: 1356-1363.

8. Benson RL, Perlman F. Clinical effects of epinephrine by inhalation. J Allergy 1948; 19: 129-140.

9. Stolley PD, Schinnar R. Association between asthma 
mortality and isoproterenol aerosols; a review. Prevent Med 1978; 7: 519-538.

10. Crane J, Pearce N, Flatt A, et al. Prescribed fenoterol and death from asthma in New Zealand,1981-83: case control study. Lancet 1989; 1: 917-922.

11. Pearce N, Grainger J, Atkinson M, et al. Case-control study of prescribed fenoterol and death from asthma in New Zealand,1977-81. Thorax 1990; 45: 170-175.

12. Grainger J, Woodman K, Pearce N, et al. Prescribed fenoterol and death from asthma in New Zealand, 19817: a further case-control study. Thorax 1991; 46: 105111.

13. Spitzer WO, Suissa S, Ernst $\mathrm{P}$, et al. The use of beta-agonists and the risk of death and near death from asthma. $N$ Engl J Med 1992; 326: 501-506.

14. Suissa S, Ernst P, Biovin J-F, et al. A cohort analysis of excess mortality in asthma and the use of inhaled betaagonists. Am J Respir Crit Care Med 1994; 149: 604-610.

15. Suissa S, Blais L, Ernst P. Patterns of increasing $\beta$-agonists use and the risk of fatal and near fatal asthma. Eur Respir J 1994; 7: 1602-1609.

16. Blais L, Ernst P, Suissa S. Confounding by indication and chanelling over time: the risks of beta-agonists. Am J Epidemiol 1996; 144: 1161-1169.

17. Garrett JE, Lanes SF, Kolbe J, Rea HH. Risks of severe life threatening asthma and beta-agonist type: an example of confounding by severity. Thorax 1996; 51: 10931099.

18. Elwood JM. Fenoterol: the evidence leading to restriction of its use. NZ Med J 1990; 103: 395-397.
19. Poole C, Lanes SF, Walker AM. Fenoterol wand fatal asthma (Letter). Lancet 1990; 335: 920.

20. Crane J, Pearce NE, Burgess C, Woodman K, Robson B, Beasley R. Markers of risk of asthma death or readmission in the 12 months following a hospital admission in the 12 months following a hospital admission for asthma. Int J Epidemiol 1992; 21: 737-744.

21. Sears MR, Taylor DR, Print CG, et al. Regular inhaled beta-agonists treatment in bronchial asthma. Lancet 1990; 336: 1391-1396.

22. Drazen JM, Israel E, Boushey HA, et al. Comparison of regularly scheduled and as-needed use of albuterol in mild asthma. N Engl J Med 1996; 335: 841-847.

23. Suissa S, Hemmelgarn B, Blais L, Ernst P. Bronchodilators and acute cardiac death. Am J Respir Crit Care Med 1996; 154: 1598-1602.

24. Crane J, Burgess C, Beasley R. Cardiovascular and hypokalaemic effects of inhaled salbutamol, fenoterol and isoprenaline. Thorax 1989; 44: 136-140.

25. Windom HH, Burgess C, Siebers R, Crane R, Purdie G, Beasley R. The pulmonary and extrapulmonary effects of inhaled beta-agonists in asthmatic patients. Clin Pharmacol Ther 1990; 48: 296-301.

26. Bremner P, Siebers R, Crane J, Pearce N, Beasley R, Burgess C. Partial versus full beta receptor agonism - a clinical study of inhaled albuterol and fenoterol. Chest 1996; 109: 957-962.

27. Newhouse MT, Chapman KR, McCallum AL, et al. Cardiovascular safety of high doses of inhaled fenoterol and albuterol in acute severe asthma. Chest 1996; 110: 595-603. 